\title{
Is A Weight-Centred Health Framework Salutogenic? Some Thoughts on Unhinging Certain Dietary Ideologies
}

\author{
LUCY APHRAMOR ${ }^{1}$ \\ ${ }^{1}$ Centre for Social Justice, Coventry University, Priory Street, Coventry CV1 5FB, UK. \\ E-mail: lucy@aphramor.freeserve.co.uk
}

\begin{abstract}
Does promoting weight loss improve health? This paper draws on diverse writings in empowerment, social justice, critical obesity literature, feminism and stress biology to challenge the appropriateness of the continued reliance on a reductionist metaphor of 'energy balance' in understanding fatness. It examines some of the scientific and philosophical premises underlying mainstream UK dietary antiobesity guidelines and argues that the evidence supporting a link between promoting weight-loss and improving health is, at best, contentious. A central theme is that the current weight-loss schema helps to naturalise a fatness discourse that not only represents large people in offensively stereotyped ways but also fails to integrate people's lived experience as gendered, situated bodies in an inequitable world.
\end{abstract}

Social Theory \& Health (2005) 3, 315-340. doi:10.1057/palgrave.sth.8700059

Keywords: obesity; fatness; stigma; dietetics; oppression; shame; social justice; health promotion; ethics

\section{BACKGROUND}

'But it is just when opinions universally prevail and we have added lip service to their authority that we become sometimes most keenly conscious that we do not believe a word that we are saying'. (Virginia Woolf, 1993)

As a dietitian sensible to issues of social justice, I have been struck by how the obesity agenda so succinctly epitomises the way in which biomedical understandings occlude critical social theory. We have been trained to (not) see in particular ways. One classic legacy of this biomedical background is the 
316

tendency to view health/obesity in individual terms. In fact, looking back, my research was catalysed by a dietetic meeting discussing high rates of coronary heart disease among Asian men in Britain. The usual suspects - fat, smoking, and exercise, chief among them - were there. Yet nobody rounded on racism. And come to think of it, I had never seen a bridge built between oppression and the heart in any of the standard texts, but surely...

I dare say we were typical of many health professionals - conscientious without conscientization (from Friere, see Freshwater, 2000). I continued to follow my nose whenever something seemed iffy in the consensus position on diseases attributed to obesity, so expertly promulgated in the literature. I have no doubt that the paths outlined for obesity treatment were well intentioned but I kept tripping up on logical inconsistencies and ethical gremlins as I dutifully tried to pursue them. In this piece, I begin to assess some of the stumbling blocks to giving a new direction to obesity research. I slip between describing obesity and adiposity as the former is so loaded and familiar a term that it can foreclose further investigation. In fact, I contend that a new route through may require fresh points of triangulation, new ways of speaking to each other about fatness that embody different connections and reveal new destinations for society. The literature is too vast for a comprehensive survey so there are inevitable omissions in my discussion: identity gets the briefest of mentions, erotophobia is all but absent, as is taste, and importantly, I confine my 'weight-loss intervention' parameters to nonsurgical treatment. However, I hope it will instil a sense of the need to integrate, rather than eclectically add-on, issues such as gender-inequity, globalization and sustainability for example - influences on fatness that are far-reaching but not far-fetched. Tackling size-discrimination is in there, alongside grief counselling skills for dietitians, but it would be disheartening if you were left wanting to smash up the scales, only. My understanding so far suggests that, if everyone is to be served equally in the obesity debacle, interrelatedness must take centre stage. And to break the gridlock, we must insist on an embodied ethics and linguistics and then allow multiple and partial perspectives to engage in a fully contextualized dialogue. Of course, quantitative knowledge, the backbone of medical narratives on obesity, has its place, but to what affect? We cannot condone injustice under the rubric of standardization and ignorance.

Does promoting weight loss improve health at large? This is the question I ask you to bear in mind. With the qualification 'dietitian', I argue that for improved congruence between practice and theoretical analyses we will have to distance ourselves from conventional wisdom, maybe even turning it on its head. 


\section{WHERE DOES SCIENCE FIT FAT?}

Monaghan, in this issue, invites us to look again at the science behind the drive for thinness. Now it appears that the clinical risks of fatness per se have been misrepresented, and the important health benefits of diet and fitness independent of weight (eg Lee et al., 1999; Blair and Church, 2004 and see Monaghan, this issue) - not to mention those arising from a certain degree of affluence and status - have somehow become lost under the sheer volume of fighting talk against fat.

Again, to reiterate, like Monaghan I am not suggesting that every fat person is healthy, anymore than every lean person is, but I do maintain that a continued focus on weight loss even on the basis of staggering failure rates alone is simply unethical. Perpetuating the 'size matters' message fuels several unwholesome narratives: that everyone who is fat is unhealthy and would be healthier and feel better if they lost weight; that weight-loss behaviour is risk free; that sustained weight loss is always and equally achievable with suitable changes and commitment at an individual level; that it is primarily the duty of the individual to fit and not an obligation for the more powerful in society to challenge narratives and address inequity, including size-based discrimination.

Relying as they do on predetermined outcome measures to indicate success and with the individual in focus, quantitative trials - the linchpin of randomized control trials (RCTs) and clinical guidelines - can easily overlook information contained in the processes involved in any change. For example, standard weight loss trails model eating as primarily a cognitive and physiological activity. Accordingly, participants' BMI is recorded at the beginning and end of intervention and when relational aspects of food consumption are included, which is rarely, they are sectioned off as an independent variable. Yet people's relationships, life events and environment - the interactional factors involved in eating behaviour - are more inseparable elements than interesting adjuncts (see Wiggins, 2002). Deemphasizing thinness and improving parenting skills, for example, have been shown to have a knock-on effect on 'normalizing' children's weight gain sometimes more so than direct dietary intervention (Golan and Crow, 2004; Golan, 2004). A first step in getting to grips with fatness may be to dismantle the old ordinances and draw up new maps.

In particular, I think of the people who are referred to dietitians for weight loss to help with joint pain in arthritis, for example. There is some evidence that quality-of-life (measured by physical health factors) improves with dietary change leading to weight loss (over an 18-month period - achieved with high levels of support - although dietary change and exercise led to 
more improvement) (Rejeski et al., 2002). Even if it was shown that it was weight loss per se and not dietary change that improved quality-of-life, we need to inquire about success rates. For, what percentage of people trying to lose weight actually succeed? The more successful interventions have a success rate of $5 \%$, a slim figure repeatedly mirrored in the literature (eg British Nutrition Foundation, 1999; Noël and Pugh, 2002). A Health Development Agency report on weight management (Mulvihill and Quigley, 2003) finds little evidence of success even when not gaining weight is included as a criterion for effectiveness. The report also states that there is no evidence for successful weight-loss interventions among minority ethnic groups in the UK. More recently, the National Institute for Clinical Evidence has reviewed RCTs to provide the best available evidence on which to base practice. Summarizing the effects of lifestyle interventions to achieve sustained weight loss, the authors concede that any weight lost is likely to be regained within 2 years (British Medical Journal, 2000). In fact, commenting on a recent review of weight-loss treatments for obesity, Professor Annie Anderson notes that 'often it seems we have policy looking for an evidence base' (Anderson, 2005). There is a recurring pattern in the medical/ dietetic literature around evidence searches for weight loss, a description of morbidity and mortality deemed to arise from obesity, the intake/output equation energetically defended, an impressive list of search engines and strategies, and a conclusion along the lines of 'controlled trails of interventions for weight loss with adequate duration and power to detect differences in mortality are lacking' combined with observations that there is 'substantial evidence documenting the difficulty of sustaining weight loss over time' (Noël and Pugh, 2002) or 'the high attrition rate $(69 \%)$ suggests that these dietary programmes were of little value to many patients who were referred to the dietetic department' (Taylor et al., 2003), and 'We found that the evidence from long-term RCTs on which to base dietary recommendations - aimed at weight loss - for obese adults was limited' (Avenell et al., 2004). That the conclusions should then unanimously call for better trials, better behaviour change skills, betternot-rewrite the question is flabbergasting. Untold numbers of people have participated in weight-loss trials and acted on dietary advice given in clinics to no good avail. What is it that happens to smother their stories or render them abserd? Encouragingly, in medicine generally some voices are allowed that call us to explore more speculative territories: 'But true improvements in efficiency come not from doing the same things more quickly or at lower cost but from doing things very differently... The biggest savings [in health care] will come not from efficiency but from reconsidering what is done.' 
The United States based National Weight Control Registry (NWCR) keeps records of people who have lost at least $14 \mathrm{~kg}$ for 1 year, and certainly the average loss of $33 \mathrm{~kg}$ for 5.5 years is significant (in Noël and Pugh, 2002). Some people can and do lose weight. However, there are only 3000 people registered in a population where $\$ 50$ billion is spent annually on weight-loss products and children, adolescents and adults increasingly engage in weightreducing behaviour, even when of 'normal' weight. The characteristics of registered 'weight-maintainers' include increased exercise, something which, returning to practice, is all too often out of reach for the disabled people my colleagues and I see in clinic. And another important variable, 'cue restriction' (avoiding scenarios where someone is likely to 'over' eat) is also irrelevant in these patient's lives: many of whom have very minimal energy (and nutrient) intakes anyway. In this case, reinforcing the myth that anyone can lose weight healthily is, at best, unprofessional, a letter to the referrer explaining why weight loss is an inappropriate treatment goal is surely a more responsible position. The reality is that we do not have effective weight-loss treatment to recommend. Somebody with joint pain might have good reason to want to lose weight but clearly being fat is not a sufficient condition for successful and sustained weight reduction to occur.

\section{ETHICS AS IF HEALTH PROMOTION MATTERED}

And with a staggering $95 \%$ failure rate, is it even ethical to recommend weight loss as a medical treatment? Are patients made aware of the high likelihood of failure, of the risks, and of any alternatives (Bacon et al., 2002, 2005; Goodman, 1995; Lyons and Miller, 1999; Miller and Jacob, 2001: throughout this article many of the references are from studies that researched people of one gender, usually women; age and ethnicity vary between studies.)? And if not, what is going wrong in obtaining informed consent? Perhaps it will take litigation from previously ill-informed patients seeking compensation for unwanted health effects associated with promoting dieting behaviour for thinness, such as - on a personal level - weight gain (see Garner and Wooley, 1991a; Field et al., 2004), compromised immunity (Nieman et al., 1997), adverse skeletal integrity (Shapses and Cifuentes, 2003), decreased dietary quality (see Ikeda et al., 1999), chronic dieting (Ikeda et al., 2004; Field et al., 2004), poor body image (Gingras et al., 2004; Bacon et al., 2005), reinforcing a sense of failure (Allan, 1994; Garner and Wooley, 1991b), detrimental influence on children's eating (eg Abramovitz and Birch, 2000), low mood (see Garner and Wooley, 1991a; Burns et al., 2001), increased risk of laxative abuse/binge eating/purging/smoking 
(eg Neumark-Sztainer et al., 1999; Fulkerson and French, 2003; Rafiroiu et al., 2003; Biener and Heaton, 1995), decreased exercise (Field et al., 2004), increased cardiovascular risk (British Nutrition Foundation, 1999; Olson et al., 2000) - before these concerns carry any real weight among the (?hapless) diet prescribers.

To re-cap, it is possible to be healthy and fat. Fat people with joint pain, for example, may in theory benefit from dietary changes and activity leading to weight loss. However, there is no effective, scientifically ratified, long-term safe dietary strategy for reducing weight. Why weight loss is recommended despite decades of well-respected research chronicling that any weight lost in active treatment will ultimately be regained and pre-treatment weight is often surpassed has more to do with stereotype (and maybe entrepreneurialism, see Taube, 2001) than science. This pseudo-health crusade has been characterized as 'the modern day equivalent of beating the insane to keep them quiet'. (Hirsch, 1978 cited in Garner and Wooley, 1991a). Prevailing attitudes towards fatness arise from selective reading of morbid-mortality, in itself influenced by unexamined attitudes on embodiment and morality. In turn this leads to an unchallenged convention in medicine/dietetics (and popular discourse: see Giles, 2003), where fatness is assumed to be inherently more risky than treatment and pressure to be thin has given rise to a new set of problems (Melcher and Bostwick, 1998; Burns and Gavey, 2004) and treatment failure leads to an intensification of efforts rather than readdressing the conceptualization of fat.

\section{GUIDELINES: WHERE IS THE EVIDENCE BASE?}

In a recent US report that cites evidence of improved mortality over the last 40 years among people deemed overweight it is suggested that improved management of cardiovascular risk factors has contributed to better health outcomes (Flegal et al., 2005). So, we could infer that when people receive appropriate treatment for disease conditions - including people who are fat mortality rates improve. This hypothesis that increased risk may not derive from fatness itself concurs with other research detailing fat people's reluctance to seek health care because of anticipated bias (Drury and Louis, 2002), difficulty exercising because of harassment (Packer, 1989) and restrictions that prevent relaxation, recreation and a sense of safety (Carryer, 2001). More research is needed to ascertain the extent to which poor clinician decisions' may contribute to poorer health outcomes (Mulvihill and Quigley, 2003). Sarlio-Lahteenkorva's (2001) qualitative research exploring weight loss and quality-of-life refers to data that indicates enhanced employment 
status, income level and relationships can all positively affect the health of people he refers to as 'reduced obese' and discusses the bi-directional and gendered nature of this dynamic. (Incidentally, his results showed adverse health habits and psychological problems among women who maintained a reduced weight such that they did not have better well-being than the 'obese' (sic) women in his study. Iatrogenesis included a burdensome body-consciousness and heightened self-surveillance.) He also points out that where discrimination against fat people exists it needs to be addressed as a human rights issue. One wonders what theoretical models organizations embrace when they list 'reduced discrimination' among the personal benefits of weight loss.

\section{IMPROVING HEALTH}

Importantly, moving away from promoting weight loss is not synonymous with dismissing the health of fat people. Far from it. The oft quoted Scottish Intercollegiate Guidelines on obesity (SIGN, 1996), a document frequently used to underscore weight-loss regimes, actually state that with lifestyle changes and independent of weight loss: 'reductions in BP occur'; 'exercise training improves glucose tolerance and insulin sensitivity'; 'in medical terms, great health gains can be achieved if a patient's smoking, dietary and exercise habits are improved to reduce risk factors'. Remember, this is independent of weight loss. So too, 'exercise protects against non-insulin dependent diabetes and cardiovascular disease irrespective of BMI'. Further support comes from the American Dietetic Association (ADA) position statement on weight loss (ADA, 2002), which states that: There is strong evidence that physical activity increases cardiorespiratory fitness with or without weight loss; activity may positively influence the distribution of body fat independent of its effect on body weight; exercise alone can reduce visceral abdominal fat, reducing risk for disease; obese (sic) fit people have lower all-cause morbidity and mortality risk than sedentary people of 'normal' weight. Monaghan (above) cites more evidence that puts the concept of disease mongering (Moynihan et al., 2002) in among the off-target message that all fat people should be encouraged to reduce weight for health reasons.

Although the SIGN guidelines explicitly note health benefits of lifestyle changes that are not consequent on weight loss, the overall tenor of the document is very much within a weight-loss imperative. Indeed, there can be few UK health practitioners who are not familiar with the SIGN claim that intentional weight loss of $10 \mathrm{~kg}$ results in many benefits, such as a $>20 \%$ fall 
in total mortality. There are probably fewer practitioners who know that this refers only to one study (Williamson et al., 1995) and holds for 'overweight' white women with existing conditions (diabetes, shortness of breath, cardiovascular disease, hypertension) and that the original authors clearly state that 'among women with no pre-existing illness, the association is equivocal' and 'similar data are not available for men, except overweight men with non-insulin dependent diabetes.' A $20 \%$ fall in total mortality is an admirable goal, but we need to be clear about the robustness of evidence behind population level exhortations to lose weight. One of the studies used to support SIGN's claims for improved lipid profiles arising from weight loss actually involved both weight loss and dietary changes, and then relied on results from only 45 adults over a 12 -week period (Hankey et al., 1995). A second study reviewing lipid modification reported on a meta-analysis; in which, only $7 \%$ of studies had over 50 people, $82 \%$ of studies had no control group, in $27 \%$ of studies people were not free-living (on a metabolic unit or not known), some studies lasted only 2-4 weeks, and exercise was not mentioned as a variable (Dattilo and Kris-Etherton, 1992). How is it that national guidelines are drawn up relying on such insubstantial data? What are the ethical and theoretical frameworks employed?

\section{THE PHYSIOLOGICAL IS THE POLITICAL}

Clinical guidelines for obesity do not stand up to scrutiny beneath their own gaze. Held out as derived from the best available evidence, current UK guidelines continue to advocate a goal that is almost certainly destined to fail. Moreover, they consistently fail to (attempt to) integrate socioeconomic factors known to impact on obesity-related conditions, a decision which alone can widen health inequalities (Aldrich et al., 2003). How does socioeconomic status (SES) influence non-communicable conditions associated with adiposity? James et al. (1997), for instance, discuss links between hypertension, cardiovascular disease and diabetes and non-weight variables related to low SES, among them viral infections, intense traffic, poor recreational facilities, low folate and antioxidant consumption, high intake of salty/fatty foods, low birth weight, adolescent pregnancy, low breastfeeding rates, low fruit and vegetable intake, low intake of fish and smoking. Other researchers investigate physiological and behavioural pathways underlying the relationship between SES and health. Where does sleep debt, for example, fit into the dominant energy-in/energy-out modelling of obesity? Van Cauter and Spiegel (1999) hypothesize that sleep deprivation - from anxiety, stress, shift work, lack of opportunity to obtain sufficient sleep, environmental 
conditions that compromise sleep quality - contributes to a high prevalence of chronic conditions in low SES groups. Decrements in sleep duration and quality decrease glucose tolerance, increase sympathetic tone and elevate evening cortisol, all of which are known risk factors for the development of insulin resistance, adiposity and/or hypertension. Alongside sleeping disturbances, poor housing, use of anxiolytics and anti-depressants, low degree of life satisfaction, low physical activity (the opportunity to exercise is socially graded), high rates of TV watching (associated with living in areas with unsafe streets), low education, unemployment, problems at work when employed and childhood social class have all been associated with obesity (Bjorntorp and Rosmond, 1999; Bjorntorp and Rosmond, 1998; Crister, 2003). And, summarizing the evidence, one researcher is confident that 'chronic stress is responsible for a greater percentage of mortalities that other risk factors including diet. These are related to control and socio-economic status' (my italics) (Harbuz, 2004). The salt in the wound is that more extreme dieting behaviours, such as diet pills and purging, are more prevalent among some of the most disadvantaged groups in society (Fulkerson and French, 2003; Neumark-Sztainer et al., 1999).

The National Health and Medical Research Council in Australia (NHMRC, 2003) has started to engage with these issues and provided guidelines on how to identify, retrieve and incorporate evidence of markers of disadvantage. Not surprisingly, they recognize that this requires a re-definition of the evidence base and search strategies. (Though, disappointingly, references to obesity treatment fall firmly within a 'lose weight' paradigm.)

In fact, there is already a significant (but to who?) body of work explicating metabolic alterations (affecting the cardiovascular, immune and neuroendocrine system) that increase the so-called 'allostatic load' among low SES groups and people living with chronic stress (eg caregivers) and have a role in the aetiology of obesity and its related conditions (eg Bjorntorp, 2001; Bjorntorp and Rosmond, 2000; Vitaliano et al., 2002). (Allostasis is the response to stress that constitutes a controlled deviation from homeostasis, within which coordinates metabolic syndrome begins to be more clearly mapped out as a stress-related disorder as we will see.) Why might people's metabolism alter according to SES? Here it may be more useful to start thinking about obesity as a consequence of metabolic syndrome, where insulin resistance and other physiological mechanisms lead to central adiposity, modifications in blood lipid profile and hypertension. Raikkonen et al. (2002) followed 425 women for an average of 7.4 years, measuring biological components of the metabolic syndrome (glucose, triglycerides, high-density lipoprotein cholesterol, waist circumference, blood pressure) and psychological risk factors (depression, anxiety, current perceived stress, 
anger). They found a reciprocal relationship between anger and the metabolic syndrome. Concluding that psychological risk factors facilitate the development of metabolic syndrome, reducing distress was one method proposed for preventing the development of metabolic syndrome. Similarly, Drapeau et al. (2003) suggest a role for stress management in the treatment of obesity. They frame adiposity as a non-optimal physiological adaptation to stress. In this scenario, stress-induced activation of the hypothalamus-pituitary-adrenal axis increases cortisol production which exerts hyperphagic and antithermogenic effects. Differential rates of responsiveness to cortisol between abdominal and subcutaneous fat, together with hormonal and enzymatic changes, mean that stress responses preferentially favour abdominal fat deposition. In healthy individuals, acute stress does not appear to lead to deleterious effects, but repeated stress may lead to long-term changes that predispose to metabolic syndrome, especially in people who are insulinresistant. On perhaps a more familiar level, stress is known to affect eating behaviour, food choices and gastrointestinal disorders (Murcott, 1998). In addition, there is recent evidence that mental stress may trigger peripheral inflammatory responses which subsequently increase morbidity and mortality (Tappy et al., 2004; Black, 2003). Genetic variability in physiological response to stress may also accentuate abdominal adiposity in some individuals.

Genetic factors are generally held to be involved in the pathogenesis of obesity-related disorders such as diabetes, insulin resistance and dyslipidaemia. Studying obesity/thinness in twins brought up separately has demonstrated a prominent role for genetics over environmental variables (see Garner and Wooley, 1991a). Genetics may help unpick the myth that fatness is solely under individual control but the gene pool alone cannot account for the swiftly rising tide of non-communicable disorders such as diabetes. Rather, insight into the interplay of the personal and social body makes an even more compelling case for us to relinquish obesity's individual culpability narrative and adopt a more mindful approach to solutions. In 1989, it was postulated that the foetal environment, as reflected in birth weight, was related to the risk of non-communicable diseases in adulthood. These reports gave rise to the foetal origins of adult disease paradigm (Breier et al., 2001; Prentice, 2003; James, 2002). Briefly, nutritionally unsound maternal diets can reset the normal course of metabolic, physiological and anatomical growth. Pathogenesis is based on altered genetic expression as adverse environmental factors reprogramme the developmental path in utero so that the child is metabolically disposed to retain fat. Low birth weight is linked to early stunting and predisposes to abdominal adiposity and metabolic syndrome in later life, possibly also mediated through altered appetite regulation. There is 
thought to be an intergenerational effect - metabolic syndrome amplifies the risk of gestational diabetes and mothers with diabetes have heavier babies prone to metabolic syndrome, early type-II diabetes, and in girls, diabetes in pregnancy, promoting an accelerating cycle of ill-health in subsequent generations. Maternal undernourishment is linked to small babies with disproportionately high measures of fat, specifically central fat. Described as the 'thin-fat' baby syndrome, researchers believe this shows that excess visceral adiposity among Asian adults can be traced back to foetal growth (see Prentice, 2003).

This phenomenon of adaptive survival strategies has become known as the 'thrifty phenotype' in relation to diabetogenesis. Notably, it emerged that this resetting of glucose regulation is 'rendered detrimental by progress' (Neel, 1968 cited in Prentice, 2003) and that a discrepancy between foetal growth and later growth rates is a good indicator of adult pathology. Anthropologist Barry Bogin has been observing the effects of a mismatch between individual's current and early environments. He refers to 'metabolic inheritance' to explain the huge one-generation gains in weight among Mayan immigrants from Guatemala now living in Florida and California. A long history of cultural and political oppression reinforces economic and nutritional deprivation among the present-day Maya, so that in a strange way, you are seeing the original trauma of conquest being played out, metabolically, in the streets of Los Angeles' (cited in Crister, 2003, p. 130). Likewise, the use of the Marshall Islands by the United States as a nuclear testing ground led to an exponential increase in fatness and metabolic syndrome among adult Marshallese. Yet in the same population over onethird of children 1-5 years are stunted. Global political and macroeconomic forces, microsocial influences including access to kin networks and cultural factors interact to shape patterns of food consumption. As one group of authors confirm, 'What can be done at the microlevel is constrained by macrolevel factors of disempowerment. In this way, issues of power and belief are played out in the bodies of individuals' (Gittelsohn et al., 2003).

In a similar vein, impaired fat oxidation resulting from childhood undernutrition could explain the high levels of fatness seen among some groups of immigrant children in nutritionally dense environments: by fifth grade, $43.4 \%$ of Mexican American boys are classed as obese (Crister, 2003, p. 131).

So, when mainstream health promotion literature reminds us of the influence of genetics and/or ethnicity on the prevalence of fatness and/or morbidity, it is incumbent upon us to resist the inclination for reductionist assumptions about pre-determined non-variables. Although well-intentioned, typically these discourses adopt a normalizing approach, wanting to bring the 
fat person down-to-size to improve their health. And in locating pathology within the individual rather than the social body they can trigger another round of harmful blanks: media influence, genetics, lack of knowledge/ willpower/motivation. Furthermore, by ignoring generational vectors, they unwittingly pay lip service to equality while cementing the fragmentation of thought and selves that fixes obesity within its contemporary, rigid, mind map. 'Obesity' has been described as 'essentially an inequalities issue in a consumerist age' (Rayner, 2005). Like 'race', 'obesity' serves as proxy for a mix of genetic, social, behavioural, occupational, intergenerational and clinical characteristics which vary by group; to treat it as a fixed, biologically specific parameter is to perpetuate pseudo-scientific rationalizations of fundamentally social constructs. Putting power, rather than chromosomes, under the microscope in the first instance may yield more effective insights: racism, ethnocentrism and violence underlie much of poor nutrition, a key player in developing metabolic syndrome.

\section{WIDENING THE PARAMETERS TO NARROW THE GAP}

In an era of evidence-based medicine, why are so many variables omitted from consideration in developing clinical guidelines? What sort of a monster are we making of 'science' by bolting it to the tenets of the so-called exclusion fallacy, where what we choose not to discuss is assumed to have no bearing on the issue? Schuftan (2003) urges us to adopt a human rights approach in reversing the consequences of globalization on health and nutrition. He advocates boldness: change will require the same kind of intellectual commitment and vigour that characterized anti-colonial or independence struggles' and visionary and radical moves that fall outside the ruling paradigm. However then, one of his references has the word love in the title, so perhaps he is a charlatan after all.

Even so, we do know that health-promotion interventions and treatment strategies based on evidence that ignores socioeconomic and life-course variables can potentially increase health inequalities (Aldrich et al., 2003). And despite various government reports that bear witness to the fact that health is to a large extent economically and socially determined, current weight-management guidelines typically adopt a behaviouristic approach to lifestyle modification. While Acheson (1998) spells out the need for social inclusion, one of government's responses to the recent House of Commons Select Committee report on obesity, fully supported by the British Dietetic Association (BDA), is personal health trainers. This individualistic stance, firmly rooted in mainstream nutrition discourse and with an unquestionable 
rhetoric of rationality as its centre of gravity, is incompatible with a philosophy and policy designed to reduce health inequalities and inequity. (In what appears to be a rare article of its kind, Gingras (2005) looks at how these individualistic values are learnt during dietetic education/socialization and what is at stake when positivistic epistemologies are routinized or contested.) Resting as it does on several shaky premises, among them the fools-gold nugget that assumes for health reasons adults can and should be lean, it myopically ignores the cornerstone put so succinctly by McDonald and ScottSamuel (2004): 'The biggest contribution government could make to improving future health and reducing inequalities would be to make gender-equitable parenting and socialization the top national political priority. There is abundant evidence that excessive masculine gender roles damage both women and men.'

However, isn't this stepping too far from the cookbook of obesity into abstract structural matters? Consider the power of the 'common-sense' heteropatriarchal ideology illustrated in the Department of Health leaflet below (Figure 1). It is this manifest gender-polarization, and interwoven

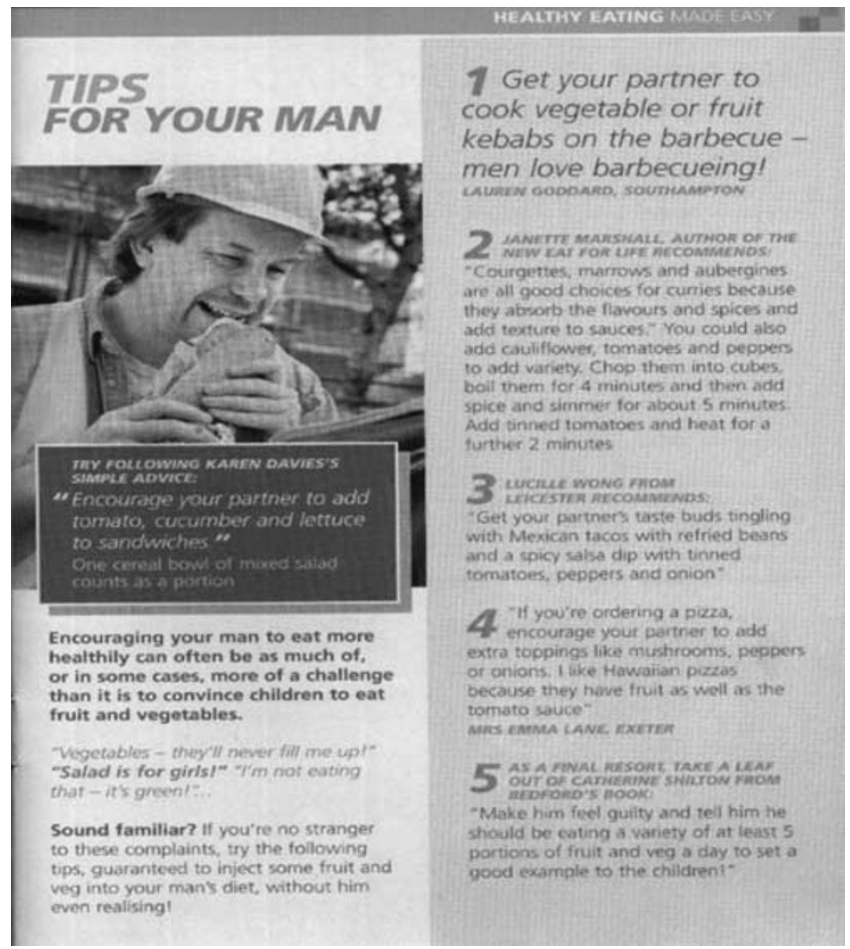

Figure 1: Department of Health, UK (2004) 5 A Day Made Easy 〈www.dh.gov.uk/healthtopics〉 
homophobia, that the psychiatrist Gilligan theorizes as the 'vector by which shame, the pathogen that transmits violence' is kept alive in society (Gilligan, 2001). And it is kept very much alive and kicking in UK dietetic discourse, where, for example, an editorial in a professional newsletter that suggested one way of getting men to access health services would be to appoint beautiful models as receptionists (Donnelly, 2004) was not seen as a matter of professional concern (personal communication). Generally lacking a qualitative (Fade, 2003), ethnographic or critical aspect (Gingras, 2005; Aphramor, 2005), the Canadian dietitian Gingras offers us the following characterization of dietetics: 'The dietetics profession represents a site of multiple and complex identities; mostly thin, non-disabled, heterosexual, white female bodies, positioned subordinately in medical hierarchies, sustained by corporeal/cultural expressions, and complicated by infinite food politics' (Gingras, 2005). In this milieu, the circulation of non-dominant mediating narratives is limited, such that Travers (1995 cited in Gingras, 2005) contends that professional dietetic discourse/ideology is complicit in constructing nutrition and health inequities.

The American Dietetic Association's position paper 'Addressing World Hunger, Malnutrition and Food Insecurity' affirms the central role of complacency around social roles and power as a nutritional issue. Poverty and poor nutrition - the precursors of adiposity and comorbidities - are feminized. Not surprisingly then, the greatest gains in improving childhood malnutrition result from moves championing gender-equity, specifically improving women's access to health care and resources (ADA, 2003).

For Sen (1984), the ordinariness of the patriarchal matrix is a barrier to accessing food at micro- and macro-levels. In his exploration (of Indian society), the battle for health then rests on thinking clearly and hinges on challenging deeply embedded value systems, often revolving around unequal gender-entitlement. Noting that 'a low key and clinically academic discussion ... is not quite adequate', he insists, 'We can do with a bit more rage, a bit more passion and anger.'

Instead, a more familiar scenario is the lax reasoning that leads to victim blaming and collusion. So, at the National Obesity Forum conference 2004, in a debate considering rationing treatment for 'obese' people, it was proposed 'The problem is simply the working class who are fat, lazy and stupid' in which case 'rather than giving them (fat people) expensive drugs we should simply sew up their stomachs.' When the ensuing laughter died down the opposer did manage to avoid another whitewash: asking delegates to substitute 'Black people' (as there are high rates of obesity and corelated morbidity in Black Afro-Caribbean people) for 'fat people' highlighted a considerable collective lack of intellectual rigour, and showed who was really 
being stitched up (Banks, 2005). Foucault's observation that 'nothing is more material, physical, corporal than the exercise of power' taps into the heart of the matter (Foucault, 1980, pp. 57-58, cited in Price, 1996). The dangerous health risks arising from the behaviour of policy makers, who are poorly motivated to really apply themselves, are amply encapsulated by Sen: 'A just society cannot be built on so much delusion.'

Or collusion. However, being so often employed, it will be some time before the masters' tools go into meltdown. Consider Greer's (2005) morbid reading of power in her obituary of the radical, and fat, feminist activist, Andrea Dworkin. Greer's article catalogues a lifetime of extreme sexual violence endured by Dworkin, from childhood onwards, before remarking that 'she never addressed her real problem, which was food.' Really.

Critics who step outside of these well-beaten perimeters serve up a more incisive argument. Larkin et al. (1996) look at the impact of sexual harassment on girls' and women's experiences of themselves in relation to eating and body management practices: how shame, violence and stigmatization are embodied. Other authors bring to our attention the long-term health, general health outcomes of sexual harassment and childhood abuse and construct pathways linking violence with eating distress, adiposity and non-communicable comorbidities (Springer et al., 2003; Dahinten, 1999; Wiederman et al., 1999; Zlotnick et al., 1996; Harned and Fitzgerald, 2002). It does not therefore follow that every fat person 'over' eats and/or has emotional problems but it does suggest that in the war against troubled eating we would do well to adjust our range of sightings.

\section{EATING: AGENDAS, DISTRESS AND DILEMMAS}

It is in the field of 'eating disorders' that fatness (understood to result from troubled eating possibly labelled as binge-eating disorder, night eating syndrome, compulsive eating, bulimia nervosa) begins to be located within a gendered dynamics of power, eating and embodiment (Heenan, in press; Katzman and Lee, 1997; Evans et al., 2002). It seems that the early maps positioning eating distress as individual pathologies, albeit with overlapping areas shaded in for a cultural milieu conducive to the rapid spread of fat phobia, were missing the point. In this perspective, while arguing the case for an awareness of cultural and emotional factors in eating behaviour leading to fatness the implicit assumption that all fat people are unhealthy and/or experience eating dilemmas requiring treatment too often goes unchallenged; comments by Buckroyd (2004) in the British Association for Counselling and 
Psychotherapy stakeholder submission to the National Institute of Clinical Guidelines draft document for obesity treatment exemplify this approach. Similarly, while early feminist texts on eating distress, notably Orbach's germinal work Fat Is A Feminist Issue (Orbach, 1978), were hugely influential in changing the contours of fat theory, as recognized elsewhere (Jackson, 1985 cited in Heenan, 1996), they too tended to collude with the idea that every fat woman eats to excess and by discovering and addressing the emotional meanings behind food and eating she can be helped to slim down. Heenan (1996) offers an accessible critique of the gendered nature of eating dilemmas and the pivotal role of women's paradoxical position in western(ized) society as both consumers and objects of consumption. She also situates her objectivity, telling us: 'As a woman, working with women's feelings about their body size and shape and about food, I am stepping into an area that touches on all aspects of my own social and inner life.' So at last, after all this heady talk about fatness, we meet a practitioner and find that she too is mindful of her body and socially interpolated. Disrupting the clean sweep of unbiased objectivity she invites us to a fully contextualized reading, an appreciation of inter-relatedness; of the text, the subject, and our own situation. And she hands us a rather rich takeaway, one that could be hard to find room for within the parameters of a biomedical container, asserting that: 'we cannot fully understand the central concern of eating disorders, a struggle to control the consumption of food and the distribution of body weight, unless we recognize that they encapsulate major themes of contemporary capitalist society's 'project of the body.' Remember, these concerns apply to huge numbers of people, not only those people with clinically recognized eating distress; dieting is so common that it has been called a 'normative discontent'. In this scenario it seems non-rational to base health promotion messages on cybernetic models that implicitly assume rationality without regard to psychoanalytic knowledge. It may not be so much empty calories as the empty self (Cushman, 1990 cited in Crossley, 2000, p. 51) that is crying out for attention. New conceptual routes through the cultural and political discourses, ideologies and silences that construct and regulate our increasingly complex and distressed relationships with food, each other and our body/mind are required (Malson and Swann, 1999; Evans et al., 2002). Globalization (see Evans et al., 2002; Schuftan, 2003), violence and oppression (Katzman and Lee, 1997; Larkin et al., 1996) help focus the picture. As Levine and Smolak (1998) remark: 'We may feel more comfortable educating young girls about the perils of dieting than we are about trying to achieve social change necessary to reduce physical and sexual victimization ... yet perhaps the latter will be more effective than the former in reducing the incidence of eating disorders.' However, who will have the guts? 
The reductionist assumptions of current theories of adiposity, its implications and significance for health, have failed to flesh out the real issues. By vilifying fatness, promoting dietary restraint, conflating slenderness with well-being, glorifying thinness, cementing gender-inequity, hiding violence, fuelling shame and perpetuating narrow biomedical understanding of health mainstream nutrition discourse marshals our thoughts and keeps the obesity generals fed with troops. In the UK, Cottam (2004) asks why we shy away from a fuller figuration of obesity. Working within the confines of the assumption that fatness is a pathological state caused by overeating as a self-destructive behaviour, she puts reports of escalating obesity rates alongside parallel trajectories for self-harm, alcohol and drug abuse to compassionately - if confusedly - silhouette the 'coping self and its deepseated troubled foundations'. Her analysis is unusual in mainstream (medical/dietetic) obesity literature by foregrounding and contextualizing the association between 'mental' ill-health and adiposity. (For accepting the formulation 'mental' ill-health without comment, where the mind/body dualism is a given, leaves intact the deep structures that keeps our thinking on its well-tracked grooves).

Significant number of people take psychiatric medication strongly associated with adiposity and/or complications of metabolic syndrome (Casey, 2005; Newcomer 2004). Indeed, the links between adiposity and emotional distress have been known for decades (Phelan et al., 2001) yet they rarely get an airing outside the specialist literature. Here, Ekpe (2001) provides a useful and transferable analysis of the concept of empowerment for people with mental health difficulties and their allies (although again wellbeing is sacrificed to weight loss per se), wherein a political action component is deemed necessary to catalyze a fundamental shift in attitudes and practice in health care. In the dietetic literature, empowerment is typically conflated with self-care/compliance/choice (empowerment) (ADA, 2002). However, the conceptual frameworks applied to obesity treatment and prevention in the UK incorporate several schematic beliefs which are anti-empowerment. Two of these are particularly pernicious. Firstly, that shame-based narratives are acceptable in dietetic discourse on weight. Monaghan (above) takes issue with derogatory images of fat people. And I would add that statements such as 'now is the time to lose those spare tyres' (BDA, 2004a, b) are equally gross. Readers curious about how alterative ways of writing can lead to a better understanding of the stories we tell, both knowingly and unknowingly, about bodies and citizenship may be interested in Bodies Out of Bounds by Evans-Braziel and LeBesco (2001). However, I transgress. Not only is this insensitivity contrary to professional codes around empathy and respect and likely to jeopardize the trust that is essential to a therapeutic relationship but 
it also insidiously contributes to counterproductive narratives - researching health improvement via lifestyle change among the Pima Indians showed that the group who attended talks that raised self-esteem fared better on biomedical markers of metabolic fitness than the control group who received standard diet and exercise sessions. (Narayan et al., 1998). For anyone struggling to see beyond the morally loaded confusion of fatuous myths, Goodman (1995) draws parallels between sizeism and other prejudices; Rogge and Greenwald (2004) discuss how and why size-discrimination can be characterized as a form of civilized oppression; and Northrop (accessed 2005), in an otherwise largely problematical paper, examines the stigmatization of obesity as a primary risk factor and the social amplification of risk. Or for hard science, consider a study that found links between internalized oppression, body fat distribution, and abnormal fasting glucose. In a group consisting of 244 African - Caribbean women in Dominica, West Indies, (Butler et al., 2002) drawn from a systematic sample of households, high levels of internalized racism were associated with larger waist circumference measurements - independent of BMI. In addition, there was a significant relationship between internalized racism and abnormal fasting glucose levels which may have been mediated through abdominal fat. This is perhaps the place to mention that national UK weight-loss campaigns typically give data for white women and men, frequently also for Asian women and men, but as far as I am aware have so far never included waist measurements for Black people, or sought to rectify this omission (BDA, personal communication).

Nevertheless, many people, especially white western women, want to be thin. Like other social movements, The National Association to Advance Fat Acceptance recognizes the way in which appearance shame militates against new understandings, individual health and political activism (Martin, 2000). Improving health for fat people will require that practitioners understand the sequelae of internalized oppression and are conversant with ways to help people contest social stigma. It will also require organizational commitment to anti-oppressive practices - which would conceivably require a period of shame-work by organizations as they realize the extent to which they have unintentionally been complicit in perpetuating bias.

A second story-line is the myth of transformation (Spitzack, 1987): the 'before and after' snaps of commercial dieting groups, the personal testimonies included in professional literature to the tune of 'I just feel so much better about myself now that I've lost weight' (BDA, 2002). Evoking feelings of guilt, anxiety and repulsion towards fatness and relying on widely accepted coercive norms to construct and normalize the self-/peer-policed autonomous subject this conception easily resonates with contemporary mind/body dualisms, where it disappears as ideology, becoming instead 
neutral 'common sense'. The associated vocabulary - gluttony, sloth, sins, good/bad, naughty, lapse, self-control, willpower, reward - invokes a restitution narrative and carries both religious and infantilizing connotations.

\section{CHANGING ATTITUDES, TRANSFORMING PRACTICE}

Given the inferior status accorded to people seen as fat in western society, and possible impairment arising from high levels of physical fatness, it would be surprising if there were no benefits accruing from weight loss. (That said, acceptable fatness levels are gendered, and some people can escape their corporeality more easily than others (Witz, 2000 cited in Monaghan, 2005; Spitzack, 1987). Indeed, saying that fatness doesnot preclude health isn't the same as saying that it is not a barrier, or that there are no advantages to being lean. As a parallel, wheelchair users may be healthy or unhealthy. For individuals in a variety of environments, impairment will have different consequences. In a society that does not afford equal rights and opportunities to disabled people, it follows that being able to walk confers many potential advantages. Some wheelchair users may indeed walk at some time. However, to imply that all wheelchair users should effectively see life as on hold until the mystical time when they can walk is patently nonsense. My own, and others (Garner and Wooley, 1991a) clinical experience attests to the currency of these 'latent lives'. The drastically revised approaches to health care that I envision do not include simply foisting a new fatness rhetoric on people. As practitioners, it is incumbent on us to be mindful: of the social context in which fat people live, the disbelief with which any healthy self-regard in the absence of weight loss is met, the size-dynamics of the health-care relationship, of feelings of grief and betrayal as the thin dream is relinquished (Melcher and Bostwick, 1998).

With societal weight stigmatization adversely affecting the fat person's health and well-being - in and beyond the health-care setting - several researchers suggest a role for health practitioners as advocates (Carryer, 2001). Levine and Smolak (1998), for example, want organizations whose mission encompasses primary prevention to direct some of their energies on using the mass media as an advocacy tool. This model of health promotion has 'the prevention specialist as scientist, researcher, activist, collaborator, artist, cultural critic and even business associate' (Murray and Ozanne, 1991 cited in Levine and Smolak, 1998). It articulates a type of activism that they believe carries enormous potential for personal-professional-social transformation needed to 'buffer and eventually reverse the weightism and sexism embodied in today's mass media' (pp. 47-48), and, I would add, nutrition 
discourse. (For a rigorous theoretical interrogation of community transformation within a coherent critical pedagogy see Ledwith, 1997).

However, why so much resistance to letting fat people be healthy and revisioning adiposity? Engaging with Sontag's observation that 'Any important disease whose causality is murky, and for which treatment is ineffective, tends to be awash in significance' (Sontag, 1978) may lead us in a fruitful direction. On one level fat people can serve as socially sanctioned scapegoats (think back to the National Obesity Forum debate and see the reference to Campos in Monaghan's paper). In other ways, fatness elsewhere can hold our collective fear of the abject, socially unacceptable aspects of our otherwise trimmed-to-fit self. A convenient depository for our forbidden appetites, it leaves us streamlined, watertight, robust paragons of selfdiscipline and rational control (Lupton, 1997, p. 75). Shildrick's feminist investigation of western philosophical traditions uncovers a core somatophobia which underlies modern thinking and upholds disciplinary regimes of the body. Appropriating postmodern theories to explore the extensive implications of binary hierarchies for biomedical thinking and practice, her analysis of ethics, embodiment and language puts us in touch with 'new possibilities of (well) being-in the-world' (p. 61).

It is instructive to note the central role Shildrick (1997) accords language and 'non-conscious ideological constraints' in fashioning medical attitudes and hence practices (p. 89). In light of this discussion so far, can culturally entrenched somatophobia and a dearth of meaningful dialogue, help to explain the foreshortened cartographies relied on around fatness? There is an epidemic of truncated theorizing. As we have seen, standards applied to researching and constructing 'obesity' frequently fall short of standards used in substantively similar fields. Many of the health-promotion strategies employed around 'weight management' are alien to a feminist or humanistic perspective. Improving health at large will require a transformation in the questions asked and the knowledge legitimated. Meanwhile, mindlessness, violence and shame are the bulking agents of the poor fare that feeds the current scourge of fat-phobia and high prevalence of noncommunicable diseases. It may well be difficult for fat people to be healthy in a climate that pathologizes, insults and oppresses difference and fatness but this is more about human rights than portion size. Adiposity emerges as a relational condition that may or may not be associated with poor health. As individuals, clinicians, researchers and policy makers we are pro-status quo or pro-reform; we can throw our weight around or we can swallow things whole.

Change will need us to be more committed, and less over determined, more thorough and less strictly disciplined in our thinking. It will ruffle 
feathers. It will require an acceptance of uncertainty, difference, and our own encumberedness and partiality. Oh, and hope.

\section{Acknowledgements}

I acknowledge the continued colliborative inspiration, support and encouragement from Jacqui Gingras. I thank Lee Monaghan for his time, support and critique and Antje Lindenmeyer for her considered review of this piece. And I am grateful to the Centre for Social Justice, Coventry University, and library staff at University Hospitals Coventry and Warwickshire NHS Trust for their generous, out-of-the-box thinking and assistance.

\section{ABOUT THE AUTHOR}

Lucy Aphramor is an Honorary Research Fellow at the Centre for Social Justice, Coventry University. She is an NHS dietitian and poet. Her interests include embodiment and the links between language and the silenced body.

\section{REFERENCES}

Abramovitz BA, Birch LL (2000). Five-year-old girls' ideas about dieting are predicted by their mothers' dieting. Journal of the American Dietetic Association 100: 1157-1163.

Acheson SD (chair) (1998). Independent Inquiry into Inequalities in Health. The Stationary Office: London.

Aldrich R, Kemp L, Harris E, Simpson S, Wilson A, McGill K, Byles J, Lowe J, Jackson T (2003). Using socioeconomic evidence in clinical practice guidelines. British Medical Journal 327: $1283-1285$.

Allan J (1994). A biomedical and feminist perspective on women's experiences with weight management. Western Journal of Nursing Research 16: 524-543.

American Dietetic Association (ADA) (2002). Weight management: position paper. Journal of the American Dietetic Association 102: 1145-1155.

American Dietetic Association (ADA) (2003). Addressing world hunger, malnutrition, and food insecurity: position paper. Journal of the American Dietetic Association 103: 1046-1057.

Anderson A (2005). Obesity prevention and management - evidence and policy (editorial). Journal of Human Nutrition and Dietetics 18: 1-2.

Aphramor L (2005). Who says size matters? Weighty Issues: Representation, Identity and Practice in the areas of Eating Disorders, Obesity and Body Management <http://staff.bath.ac.uk/psssr/ weightyissues-spkrs.htm >. Accessed 27 April 2005.

Avenell A, Brown T, McGee MA, Campbell MK, Grant AM, Broom J, Jung RT, Smith WCS (2004). What are the long-term benefits of weight reducing diets in adults? A systematic review of randomized control trials. Journal of Human Nutrition and Dietetics 17: 317-335.

Bacon L, Keim NL, Van Loan MD, Derricote M, Gale B, Kazaks A, Stern JS (2002). Evaluating a 'nondiet' wellness intervention for improvement in metabolic fitness, psychological well-being and eating and activity behaviors. International Journal of Obesity and Related Metabolic Disorders 26: 854-865.

Bacon L, Stern J, Van Loan M, Keim NL (2005). Size acceptance and intuitive eating improves health for obese, female chronic dieters. Journal of the American Dietetic Association 105: 929-936. 


\section{Aphramor \\ Is A Weight-Centred Health Framework Salutogenic?}

336

Banks I (2005). Rationing care for obese people: a round figure. Journal of the National Obesity Forum 10: 11.

Biener L, Heaton A (1995). Women dieters of normal weight: their motives, goals, and risks. American Journal of Public Health 85: 714-717.

Black PH (2003). The inflammatory response is an integral part of the stress response: implications for atherosclerosis, insulin resistance, type II diabetes and metabolic syndrome X. Brain, Behavior and Immunity 17: 350-364.

Bjorntorp P (2001). Do stress reactions cause abdominal obesity and comorbidities? Obesity Reviews 2: $73-86$.

Bjorntorp P, Rosmond R (1998). Psychiatric ill-health of women and its relationship to obesity and body fat distribution. Obesity Reviews 6: 338-345.

Bjorntorp P, Rosmond R (1999). Psychosocial and socio-economic factors in women and their relationship to obesity and regional body fat distribution. International Journal of Obesity and Related Metabolic Disorders 23: 138-145.

Bjorntorp P, Rosmond R (2000). Neuroendocrine abnormalities in visceral obesity. International Journal of Obesity and Related Metabolic Disorders 24(Suppl 2): S80-S85.

Blair SN, Church TS (2004). The fitness, obesity and health equation. Is physical activity the common denominator? Journal of the American Medical Association 292: 1232-1234.

Breier BH, Vickers MH, Ikenasio BA, Chan KY, Wong WP (2001). Fetal programming of appetite and obesity. Molecular and Cellular Endocrinology. 185: 73-79.

British Dietetic Association (2002). Be weight wise: why being a healthy weight is so important. Weight Wise Fact Sheet 1.

British Dietetic Association (2004a). Response to choosing health: making healthier choices easier. Accessed 2 December 2005, www.bda.uk.com/Downloads/whitepaperresponse.pdf.

British Dietetic Association (2004b). Media statement. Obesity 27 May. Accessed 2 December 2005, www.bda.uk.com/Downloads/obesitymediastatement.pdf.

British Medical Journal (2000). Clinical Evidence. Concise Version Issue 4. British Medical Journal Publishing Group: London.

British Nutrition Foundation (1999). Obesity. The Report of the British Nutrition Foundation Task Force. Blackwell Science: London.

Buckroyd J (2004). Argument by Professor Julia Buckroyd, University of Hertfordshire. 〈www. bacp.co.uk/notice_board/responses/NICE_obesity_scope_04.doc > Accessed 13 June 2005.

Burns CM, Tijhuis MA, Seidell JC (2001). The relationship between quality of life and perceived body weight and dieting history in dutch men and women. International Journal of Obesity and Related Metabolic Disorders 25: 1386-1392.

Burns M, Gavey N (2004). 'Healthy weight' at what cost? 'Bulimia' and a discourse of weight control. Journal of Health Psychology 9: 549-565.

Butler C, Tull ES, Chambers EC, Taylor J (2002). Internalised racism, body fat distribution, and abnormal fasting glucose among African-Caribbean women in Dominica, West Indies. Journal of the National Medical Association 94: 143-148.

Carryer J (2001). Embodied largeness: a significant women's health issue. Nursing Inquiry 8: 90-97.

Casey DE (2005). Metabolic issues and cardiovascular disease in patients with psychiatric disorders. American Journal of Medicine 118(Suppl 2): 15S-22S.

Cottam R (2004). Obesity and culture. The Lancet 364: 1202-1203.

Crister G (2003). Fat Land: How Americans Became the Fattest People in the World. Penguin: England.

Crossley M (2000). Rethinking Health Psychology. Open University Press: Buckingham.

Dahinten VS (1999). Peer sexual harassment: a barrier to the health of adolescent females? Canadian Journal of Nursing Research 31: 41-52.

Dattilo AM, Kris-Etherton PM (1992). Effects of weight reduction on blood lipids and lipoproteins: a meta-analysis. American Journal of Clinical Nutrition 56: 320-328. 
Donnelly N (2004). From the editor. Dietetic Adviser Issue 2. British Dietetic Association: Birmingham.

Drapeau V, Therrien F, Richard D, Tremblay A (2003). Is visceral obesity a physiological adaptation to stress? Panminerva Medicine 45: 189-195.

Drury CA, Louis M (2002). Exploring the association between body weight, stigma of obesity and health care avoidance. Journal of the American Academy of Nurse Practice 14: 554-561.

Ekpe H (2001). Empowerment for adults with chronic mental health problems and obesity. Nursing Standard 15, 13: 37-42.

Evans J, Evans R, EvansC, Evans JE (2002). Fat free schooling: the discursive production of ill-health. International Studies in Sociology of Education 12: 191-212.

Evans-Braziel J, LeBesco K (2001). Bodies Out of Bounds: Fatness and Transgression. University of California Press: London.

Fade S (2003). Communicating and judging the quality of qualitative research: the need for a new language. Journal of Human Nutrition and Dietetics 16: 139-149.

Field AE, Manson JE, Taylor CB, Willett WC, Colditz GA (2004). Association of weight change, weight control practices, and weight cycling among women in the Nurses' Health Study II. International Journal of Obesity and Related Metabolic Disorders 28: 1134-1142.

Flegal KM, Graubard BI, Williamson DF, Gail MH (2005). Excess deaths associated with underweight, overweight, and obesity. Journal of the American Medical Association 293: 1861-1867.

Freshwater D (2000). Against cultural narration in nursing. Journal of Advanced Nursing Practice 32: 481-484.

Fulkerson JA, French SA (2003). Cigarette smoking for weight loss or control among adolescents: gender and racial/ethnic differences. Journal of Adolescent Health 32: 306-313.

Garner D, Wooley SC (1991a). Confronting the failure of behavioral and dietary treatments for obesity. Clinical Psychology Review. 11: 729-780.

Garner D, Wooley SC (1991b). Obesity treatments: the high cost of false hope. Journal of the American Dietetic Association 91: 1248-1251.

Giles D (2003). Narratives of obesity as presented in the context of a television talk show. Journal of Health Psychology 8: 317-326.

Gilligan J (2001). Preventing Violence. Thames and Hudson: New York.

Gingras J (2005) (forthcoming; personal communication).

Gingras J, Fitzpatrick J, McCargar L (2004). Body image of chronic dieters: lowered appearance evaluation and body satisfaction. Journal of the American Dietetic Association 104: 1589-1592.

Golan M (2004). Targeting parents exclusively in the treatment of childhood obesity: long-term results. Obesity Reviews 12: 357-361.

Golan M, Crow S (2004). Parents are key players in the prevention and treatment of weight-related problems. Nutrition Reviews 62: 39-50.

Gittelsohn J, Haberie H, Vastine AE, Dyckman W, Palafox NA (2003). Macro- and microlevel processes affect food choice and nutritional status in the republic of the marshall islands. The Journal of Nutrition 1333: 310S-313S.

Goodman WC (1995). The Invisible Woman: Confronting Weight Prejudice In America. Gûrze Books: United States of America.

Greer G (2005). Larger than life warrior with the r word and a righteous fury. The Times, Thursday April 14. p. 21.

Hankey CR, Rumley ALowe GDO, Lean MEJ (1995). Weight loss improves thrombotic and rheological risk factors for ischaemic heart disease. Proceedings of the Nutrition Society 54(Part 2): 94A.

Harbuz M (2004). Psychosomatic and unexplained symptoms in general practice: an integrated approach. The Journal of Primary Care Mental Health 7: 100-104. 
Harned MS, Fitzgerald LF (2002). Understanding a link between sexual harassment and eating disorder symptoms: a mediational analysis. Journal of Consulting and Clinical Psychology 70: 1170-1181.

Heenan MC (1996). Women, food and fat: too many cooks in the kitchen?. In: Burman E et al. (eds). Challenging Women: Psychology's Exclusions, Feminist Possibilities. Open University Press: Buckingham, England.

Heenan MC (in press) 'Looking in the fridge for feelings': the gendered psychodynamics of consumer culture. In: Davidson J, Bondi L and Smith M (eds). Emotional Geographies. Burlington, VT \& Aldershot: Ashgate.

Ikeda J, Hayes D, Satter E, Parham ES, Kratina K, Woolsay M, Lowey M, Tribole E (1999). A commentary on the new obesity guidelines from NIH. Journal of the American Dietetic Association 99: 918-920.

Ikeda JP, Lyons P, Schwartzman F, Mitchell RA (2004). Self-reported dieting experiences of women with body mass indexes of 30 or more. Journal of the American Dietetic Association 104: 972-974.

James WP (2002). Will feeding mothers prevent the Asian metabolic syndrome epidemic? Asia Pacific Journal of Clinical Nutrition 11 (Suppl 3): S516-S523.

James WPT, Nelson M, Ralph A, Leather S (1997). Socioeconomic determinants of health: the contribution of nutrition to inequalities in health. British Medical Journal 314: 1545-1549.

Katzman MA, Lee S (1997). Beyond body image: the integration of feminist and transcultural theories in the understanding of self starvation. International Journal of Eating Disorders 22: 385-394.

Larkin J, Rice C, Russell V (1996). Slipping through the cracks: sexual harassment, eating problems, and the problem of embodiment. Eating Disorders 4: 5-26.

Ledwith M (1997). Participating in Transformation: Towards a Working Model of Community Empowerment. Venture Press: Birmingham.

Lee CD, Blair SN, Jackson AS (1999). Cardiorespiratory fitness, body composition, and all-cause and cardiovascular disease mortality in men. American Journal of Clinical Nutrition 69: 373-380.

Levine M, Smolak L (1998). The Mass media and disordered eating. In: Vandereycken W and Noordenbos G (eds). Prevention of Eating Disorders. The Athlone Press: London.

Lupton D (1997). The Imperative of Health: Public Health and the Regulated Body. Sage: London.

Lyons P, Miller W (1999). Effective health promotion and clinical care for large people. Medicine and Science in Sports and Exercise 31: 1141-1146.

Malson H, Swann C (1999). Prepared for consumption: (dis)orders of eating and embodiment. Journal of Community and Applied Social Psychology 9: 397-405.

Martin D (2000). Organizational approaches to shame: avowal, management and contestation. Sociological Quarterly 41: 125-150.

McDonald R, Scott-Samuel A (2004). Missed opportunities? Wanless and the White Paper. Public Health News 24: 10-12.

Melcher J, Bostwick G (1998). The obese client: myths, facts, assessment and intervention. Health and Social Work 23: 195-103.

Miller WC, Jacob AV (2001). The health at any size paradigm for obesity treatment: the scientific evidence. Obesity Reviews 2: 37-45.

Monaghan LF (2005). Big handsome men, bears and others: virtual constructions of 'fat male embodiment'. Body and Society 11: 79-109.

Moynihan R, Heath I, Henry D (2002). Selling sickness: the pharmaceutical industry and disease mongering. British Medical Journal 324: 886-891.

Mulvihill C, Quigley R (2003). The Management of Obesity and Overweight: An Analysis Of Reviews Of Diet, Physical Activity And Behavioural Approaches 1st edition. Health Development Agency: London. 
Murcott A (1998). The Nation's Diet: Social Science of Food Choice. Longman: London.

Narayan KM, Hoskin M, Kozak D, Kriska AM, Hanson RL, Pettitt DJ, Nagi DK, Bennett PH, Knowler WC (1998). Randomized clinical trial of lifestyle interventions in Pima Indians: a pilot study. Diabetes Medicine 15: 66-72.

National Health and Medical Research Council (2003). Using Socioeconomic Evidence in Clinical Practice Guidelines. Commonwealth of Australia. www.nhmrc.gov.au/publications/synopses/ cp65syn.htm.

National Weight Control Registry. NWCR. www.uchsc.edu/nutrition/nwcr.htm.

Neumark-Sztainer D, Sherwood NE, French SA, Jeffry RW (1999). Weight control behaviors among adult men and women: a cause for concern? Obesity Research 7: 179-188.

Newcomer JW (2004). Metabolic risk during anti-psychotic treatment. Clinical Therapeutics 26: 1936-1946.

Nieman DC, Nehlsen-Cannarella SL, Henson DA, Koch AJ, Butterworth DE, Fagoaga OR, Utter A (1997). Immune response to exercise training and/or energy restriction in obese women. Medicine and Science in Sport and Exercise 30: 679-686.

Noël PH, Pugh JA (2002). Management of overweight and obese adults. British Medical Journal 325: 757-761.

Northrop M (2005). The Social Amplification of Risk in Relation to Obesity www.kent.ac.uk/scarr/ events/finalpapers/Northrop.pdf. Accessed 16 June 2005.

Obesity in Scotland (1996). Integrating Prevention with Weight Management: A National Clinical Guideline Recommended for Use in Scotland by the Scottish Intercollegiate Guidelines Network. SIGN Publication Number 8, Edinburgh, Scotland.

Olson MB, Kelsey SF, Bittner V, Reis SE, Reichek N, Handberg EM, Merz CN (2000). Weight cycling and high-density lipoprotein cholesterol in women: evidence of an adverse effect. Journal of the American College of Cardiology 36: 1565-1571.

Orbach S (1978). Fat Is A Feminist Issue. Paddington Press: London.

Packer J (1989). The role of stigmatization in fat people's avoidance of physical exercise. In: Brown L, Rothblum E (eds). Fat Acceptance and Psychotherapy. Haworth Press: New York. pp. 49-63.

Phelan M, Stradins L, Morrison S (2001). Physical health of people with severe mental illness (editorial). British Medical Journal 322: 433-444.

Prentice AM (2003). Intrauterine Factors, Adiposity and Hyperinsulinaemia. British Medical Journal 327: $880-881$.

Price J (1996). The marginal politics of our bodies? Women's health, the disability movement, and power. In: Humphries B (ed). Critical Perspectives on Empowerment. Venture Press: Birmingham.

Rafiroiu C, Sargent RG, Parra-Medina D, Drane WJ, Valois RF (2003). Covariations of adolescent weight-control, health-risk and health-promoting behaviors. American Journal of Health Behavior 27: $3-14$

Raikkonen K, Matthews KA, Kuller LH (2002). The relationship between psychological risk attributes and the metabolic syndrome in healthy women: antecedent or consequence? Metabolism 51: 1573-1577.

Rayner G (2005). The politics of fat. Public Health News, 24 January. p. 9.

Rejeski WJ, Focht BC, Messier SP, Morgan T, Pahor M, Penninx B (2002). Obese, older adults with knee osteoarthritis: weight loss, exercise, and quality of life. Health Psychology 21: 419-426.

Rogge MM, Greenwald M (2004). Obesity, stigma and civilized oppression. Advances in Nursing Science 27: 301-315.

Sarlio-Lahteenkorva S (2001). Weight loss and quality of life among obese people. Social Indicators Research 54: 329-346.

Sen A (1984). Food battles: conflicts in the access to food. Food and Nutrition 10: 81-89.

Shapses S, Cifuentes M (2003). Nutritional aspects of bone health. In: New S, Bonjour JP (eds). Weight Reduction and Bone Health. RSC: UK. pp. 589-608. 
Schuftan C (2003). Poverty and inequity in an era of globalization: our need to change and to reconceptualize. International Journal for Equity in Health 2: 4 〈http://www.equityhealthj.com/ content $/ 2 / 1 / 4\rangle$.

Shildrick M (1997). Leaky Bodies and Boundaries: Feminism, Postmodernism and (Bio) Ethics. Routledge: London.

Sontag S (1978). Illness as Metaphor. Penguin Books: England.

Spitzack C (1987). Confession and signification: the systematic inscription of body consciousness. The Journal of Medicine and Philosophy 12: 357-369.

Springer KW, Sheridan J, Kuo D, Carnes M (2003). The long-term health outcomes of childhood abuse. An overview and call to action. Journal of General Internal Medicine 18: 864-870.

Tappy L, Seematter G, Martin J-L (2004). Environmental influences on diseases in later life. In: Allison SP, Go VLW (eds). Metabolic Issues of Clinical Nutrition. Nestle Nutrition Workshop Series Clinicall and Performnance Program. Nestec Ltd.: Basel. pp. 19-35.

Taube G (2001). The soft science of dietary fat. Science 291: 2536-2545.

Taylor FC, Irons LJ, Finn P, Summerbell CD (2003). Controlled clinical trial of two weight reducing diets in a NHS hospital dietetic outpatient clinic - a pilot study. Journal of Human Nutrition and Dietetics 16: 85-89.

Van Cauter E, Spiegel K (1999). Sleep as a mediator of the relationship between socioeconomic status and health: a hypothesis. Annals New York Academy of Sciences 896: 254-261.

Vitaliano PP, Scanlon JM, Zhang J, Savage MV, Hirsch IB, Siegler IC (2002). A path model of chronic stress, the metabolic syndrome, and coronary heart disease. Psychosomatic Medicine 64: 418-435.

Wiederman MW, Sansone RA, Sansone LA (1999). Obesity among sexually abused women: an adaptive function for some? Women's Health 29: 89-100.

Wiggins S (2002). Talking with your mouth full: gustatory Mmms and the embodiment of pleasure. Research on Language and Social Interaction 35: 311-336.

Williamson DF, Pamuk E, Thun M, Flanders D, Byers T, Health C (1995). Prospective study of intentional weight loss and mortality in never-smoking overweight US white women aged 40-64 years. American Journal of Epidemiology 141: 1128-1141.

Woolf V (1993). How It Strikes a Contemporary. In The Crowded Dance of Modern Life. Penguin: London. p. 27.

Zlotnick C, Hohlstein LA, Shea MT, Pearlstein T, Recupero P, Bidadi K (1996). The relationship between sexual abuse and eating pathology. International Journal of Eating Disorders 20: 129-134. 